\title{
Multispectral imaging system using 12 interference filters for mapping pigments
}

\author{
Antonino Cosentino \\ Cultural Heritage Science Open Source, Piazza Cantarella 11, Aci Sant'Antonio, 95025, Italy \\ antoninocose@gmail.com
}

\begin{abstract}
Multispectral imaging systems are used in art examination in order to map pigments and binders as well as retouches. This work presents a simple system composed of a monochromatic CCD camera and a set of only 12 interference filters characterized by different bandwidths and spacing throughout the covered electromagnetic spectrum $(400-805 \mathrm{~nm})$. The reasoning supporting the selection of these specific filters is discussed, as well as the results obtained on a collection of 54 historical pigments and on a series of $18^{\text {th }}$ century frescoes in Sicily. Generally, the filters set for similar systems are chosen equally spaced across the recorded spectrum. For this study the centre wavelength and the bandwidth of these filters have been chosen accordingly to the spectral features of historical pigments. This system allows only for a qualitative reconstruction of pigments reflectance spectra. It must be considered a valuable tool for segmenting the images of polychrome artworks and to identify areas of interest for further analytical examinations if more conclusive results are necessary.
\end{abstract}

Sistema multiespectral de imagem com 12 filtros de interferência para mapeamento de pigmentos

\section{Resumo}

Os sistemas multiespectrais de imagem são utilizados na análise de obras de arte para mapear e identificar pigmentos e aglutinantes, bem como reintegrações cromáticas. Este trabalho apresenta um sistema simples composto por uma câmara CCD monocromática e um conjunto de apenas 12 filtros de interferência caracterizados por diferente espaçamento e largura das bandas ao longo do espectro electromagnético (400-805 nm). É justificada a selecção destes filtros e são discutidos os resultados obtidos quer com um conjunto de 54 pigmentos históricos quer com algumas pinturas a fresco, do século XVIII, da Sicília. De uma forma geral, os filtros usados em sistemas semelhantes são espaçados ao longo do espectro, mas, neste estudo, o comprimento de onda central e a largura da banda dos filtros foram seleccionados de modo a melhorar a representação das características espectrais dos pigmentos históricos. Este sistema permite apenas a reconstituição qualitativa dos espectros de reflectância. Deve ser considerado um instrumento útil para a segmentação de imagens de obras de arte polícromas e identificação de áreas de interesse para exame analítico mais detalhado se forem necessários resultados mais conclusivos.

\section{Keywords}

Reflectance spectroscopy Spectral reflectance

Multispectral imaging Pigments identification Art conservation

\section{Palavras-chave}

Espectroscopia de reflectância Reflectância espectral Imagem multiespectral Identificação de pigmentos Conservação de arte

ISSN 2182-9942 


\section{Introduction}

Reflectance imaging spectroscopy is used to remotely map and identify materials in a number of industry applications. It is generally performed with monochromatic cameras: a CCD sensor for the UV-VISNIR (near infrared) (about 360-1100 nm) range, and a much more expensive InGaAs camera for the SWIR (short wave infrared) $(900-1700 \mathrm{~nm})$ range. The CCD camera allows to observe the electronic transitions responsible in part for the colour of the pigments, while the SWIR camera permits to study their vibrational overtones, which are also characteristic. Both of these cameras must be equipped with an appropriate wavelength selection system, the simplest being a series of bandpass interference filters. Such a system captures images of an object in a series of spectral bands, which can then be used to reconstruct a reflectance spectrum for each pixel of the scene. Once the images are registered and calibrated, they are uploaded in the reflectance image cube, where the images are represented by the $X$ and $Y$ axes and the $Z$ dimension denotes the wavelength of the image. From the cube, it is then possible to reconstruct the reflectance spectrum of each pixel. These systems are called multispectral or hyperspectral imagers, the difference relies on the number of spectral images produced; less than a dozen for the first [1-5], and much more for the hyperspectral systems which can use tunable filters (liquid-crystal tunable filters (LCTF) [6], acousto-optical tunable filter (AOTF) [7] or grating spectrometers [8] to provide hundreds of spectral images. The possibility of using an RGB digital camera rather than a monochromatic one $[9,10]$ was also tested. It is necessary to point out that multispectral imaging has been also referred to in the art conservation sector as the method consisting in acquiring a collection of broad spectral band images (multimodal images) realized with different sensors and lighting sources, such as ultraviolet fluorescence photos, infrared reflectograms and x-ray radiographs [11].

Multispectral and Hyperspectral imaging systems have been applied for art examination in order to map and identify artists' materials in paintings (pigments [1, $3,12]$ and binders, such as animal glue and egg tempera [13]) and to detect damages and retouches. They are also used to visually enhance old documents [14-16]. It has been shown $[3,5]$ that even when pigments are mixed or glazed, the method can provide conclusive identification, though usually micro-invasive and non-invasive analytical examinations are recommended to confirm the results and to provide more detailed information. Nonetheless, reflectance imaging-spectroscopy can successfully assist with making conservation decisions and it provides important information on the materials present.

There is the need in the art conservation field of an affordable multispectral imaging system for the mapping and tentative identification of historical pigments on artworks. At first, in the last decade, systems using few and large spectral bands were commercialized, such as Artist
[17]. These systems do not allow to reconstruct spectral reflectance and they are used only for qualitative inspection of the images. Later on, costly systems achieving much more narrow resolution using a tunable optical filter were introduced, such as Sepia [17] and Musis [18], providing 70 and 34 spectral bands, respectively. Another solution is represented by a scanner mounting a filtered photomultiplier array [19, 20]. All those instruments as well as many others [3, 21-22] reconstruct the reflectance spectra by measuring the spectral reflectance directly on every filter point. Another method consists in a complex computational reconstruction of the reflectance spectra from few large bandpass and long pass filters [2, 9, 10, 23]. This approach was developed in order to minimize the radiation on the target since the acquisition is faster but it requires advanced computational skills.

This paper deals with the first method consisting in measuring the spectral reflectance directly on every filter point and introduce and evaluates a set of 12 interference bandpass filters that are not equally spaced and have different bandwidth. This filters set coupled with a monochromatic camera is proposed as an affordable and simple multispectral imager for artworks. Generally, the filters are chosen equally spaced across the recorded spectrum. A set of 12 filters with spectral intervals (50 $\mathrm{nm})$ and FWHM (40 nm) was used successfully [1, 24] to map the limited set of pigments used in manuscript illuminations. Other studies use a combination of narrow and relatively large bandpass filters [25]. More filters, such as 18 [21], allows for higher resolution. While a large number of narrow interference filters provide higher spectral resolution, it also implies higher costs and more technical difficulties in the acquisition of the images; narrow bandpass filters need high intensity lighting, a condition that could be either prohibitive for light sensitive art objects, or unpractical for large art works such as frescoes.

The centre wavelength and the bandwidth of these selected filters have been chosen in order to better represent the spectral features of the 54 historical pigments. Filters have been chosen from a commercially available catalogue and this set does not claim to be the best conceivable since the limited wavelengths and bandwidths available. On the other hand, this work represents an initial study on the advantages of using filters selected ad-hoc (bandwidth and center wavelength), rather than equally spaced ones for the specific task of mapping historical pigments and segmenting images of polychrome artworks.

\section{Experimental}

The multispectral system is composed of a PixelTeq SpectroCam VIS CCD camera and 12 interference filters commercialized by the same company. SpectroCam VIS camera incorporates a high-sensitivity 5 megapixels CCD covering the range $360-1000 \mathrm{~nm}$ and a sequential 8-band filter-wheel. The 12 filters selected were 
changed manually thanks to the easy access of the filter holders avoiding misplacement of the camera. The calibration of the images was performed using as reflectance standard the AIC (American Institute of Conservation) photo target which was added to the scene. Its white, black and 4 grey patches were used to calibrate the images by applying a multi-point 3rd degree polynomial calibration curve using ImageJ [26]. These patches are manufactured by X-Rite and they are identical to those used in the X-Rite Color Checker and Color Checker Passport. The patches are identified by the following designations (white to black): white; N8; N6.5; N5; N3.5; and black. In the Munsell notation the corresponding chroma is $9.5,8,6.6,5,3.5,2$, their sRGB are 243,200 , $160,122,85,52$ and the reflectance across the 400-805 $\mathrm{nm}$ range covered by the interference filters is uniform. The multi-point 3rd degree polynomial calibration using the 6 swatches sRGB values allowed to correct for the spectral response of the CCD across the spectrum and to normalize the spectral images based on the white swatch. The images were then registered using ImageJ. The reflectance spectra reconstructed from the 12 multispectral images will be referred to with the acronym MSI-12 and will be represented in the figures with dotted lines. The system was setup to register images in the VIS-NIR range only, and it was chosen to completely disregard the UV. Thus, standard halogen lamps ( $2 \times 400 \mathrm{~W}$ and $2 \times 1000 \mathrm{~W}$ for the frescoes) were used. The multispectral imager was tested on a board composed of 54 swatches of historical pigments which have been applied using gum arabic as a binder, on cellulose and cotton watercolour paper, acids and lignin free; hereafter referred to as pigments checker, Figure 1a. Two cross-hair lines, $0.2 \mathrm{~mm}$ (vertical) and $0.4 \mathrm{~mm}$ (horizontal), were printed on each swatch of paper before the application of paint, in order to have a means to evaluate the pigment transparency in the infrared. The pigments were mulled into the binder which was added as needed for each pigment and applied with brush. No other means to control and measure thickness of the paint and ratio binder-pigment was implemented. All the pigments are commercially available from Kremer Pigments (Germany) and information regarding their composition and manufacturing processes is available on the company website. Table 1 shows the name and product code of each pigment. This board was previously documented with technical photography and infrared reflectography [27] and with FORS (Fiber Optics Reflectance Spectroscopy) [28]. All the FORS spectra presented in this paper belong to the downloadable online FORS spectra of historical pigments introduced in the same publication which also comprehensively describes the FORS equipment used.

\section{Results and discussion}

When seeking to establish the specifics of the set of 12 filters, it seemed useful to carefully select bandwidth
Table 1

Distribution by color of the 54 historical pigments (Kremer Pigments) studied in this paper and respective product code

\begin{tabular}{|c|c|}
\hline Color & Pigment \\
\hline Blacks & $\begin{array}{l}\text { Ivory black, } 12000 \\
\text { Vine black, } 47000 \\
\text { Bone black, } 47100 \\
\text { Lamp black, } 47250\end{array}$ \\
\hline Browns & $\begin{array}{l}\text { Burnt Sienna, } 40430 \\
\text { Burnt umber, } 40710 \\
\text { Van Dyke brown, } 41000 \\
\text { Raw Sienna, } 17050 \\
\text { Raw umber, } 40610\end{array}$ \\
\hline Whites & $\begin{array}{l}\text { Lead white, } 46000 \\
\text { Zinc white, } 46300 \\
\text { Lithopone, } 46100 \\
\text { Titanium white, } 46200 \\
\text { Gypsum, } 58300 \\
\text { Chalk, } 58000\end{array}$ \\
\hline Blues & $\begin{array}{l}\text { Azurite, } 10200 \\
\text { Blue bice, } 10184 \\
\text { Cobalt blue, } 45730 \\
\text { Egyptian blue, } 10060 \\
\text { Indigo, } 36005 \\
\text { Maya blue, } 36007 \\
\text { Prussian blue, } 45202 \\
\text { Smalt, 10000 } \\
\text { Ultramarine natural, } 10510 \\
\text { Phthalo blue, } 23050 \\
\text { Cobalt violet, } 45800\end{array}$ \\
\hline Greens & $\begin{array}{l}\text { Cadmium green, } 44510 \\
\text { Chrome green, } 44200 \\
\text { Cobalt green, } 44100 \\
\text { Green earth, } 11000 \\
\text { Malachite, } 10300 \\
\text { Phthalo green, } 23000 \\
\text { Verdigris, } 44450 \\
\text { Viridian, } 44250\end{array}$ \\
\hline Reds & $\begin{array}{l}\text { Alizarin, } 23600 \\
\text { Cadmium red, } 21120 \\
\text { Red lead, } 42500 \\
\text { Red ocher, } 11574 \\
\text { Vermilion, } 10610 \\
\text { Madder lake, } 372051 \\
\text { Lac dye, 36020 } \\
\text { Carmine lake, } 42100 \\
\text { Realgar, 10800 }\end{array}$ \\
\hline Yellows & $\begin{array}{l}\text { Cadmium yellow, } 21010 \\
\text { Cobalt yellow, 43500 } \\
\text { Lead Tin yellow I, } 10100 \\
\text { Lead Tin yellow II, } 10120 \\
\text { Massicot, } 43010 \\
\text { Naples yellow, } 10130 \\
\text { Orpiment, } 10700 \\
\text { Saffron, } 36300 \\
\text { Yellow ocher, } 40010 \\
\text { Yellow Lake made of Reseda, } 36262 \\
\text { Gamboge, } 37050\end{array}$ \\
\hline
\end{tabular}

and centre wavelength in order to represent the specific features that characterize historical pigments. In fact, most of the electronic transitions in the blue and green regions are broad and therefore can be recorded with lower resolution using comparatively large bandwidth filters $(50 \mathrm{~nm})$. On the other hand, most of the sharp inflection points of the yellow and red pigments, as well as the characteristic S-shape of the iron-based earths, are in the red and infrared regions, and need higher 

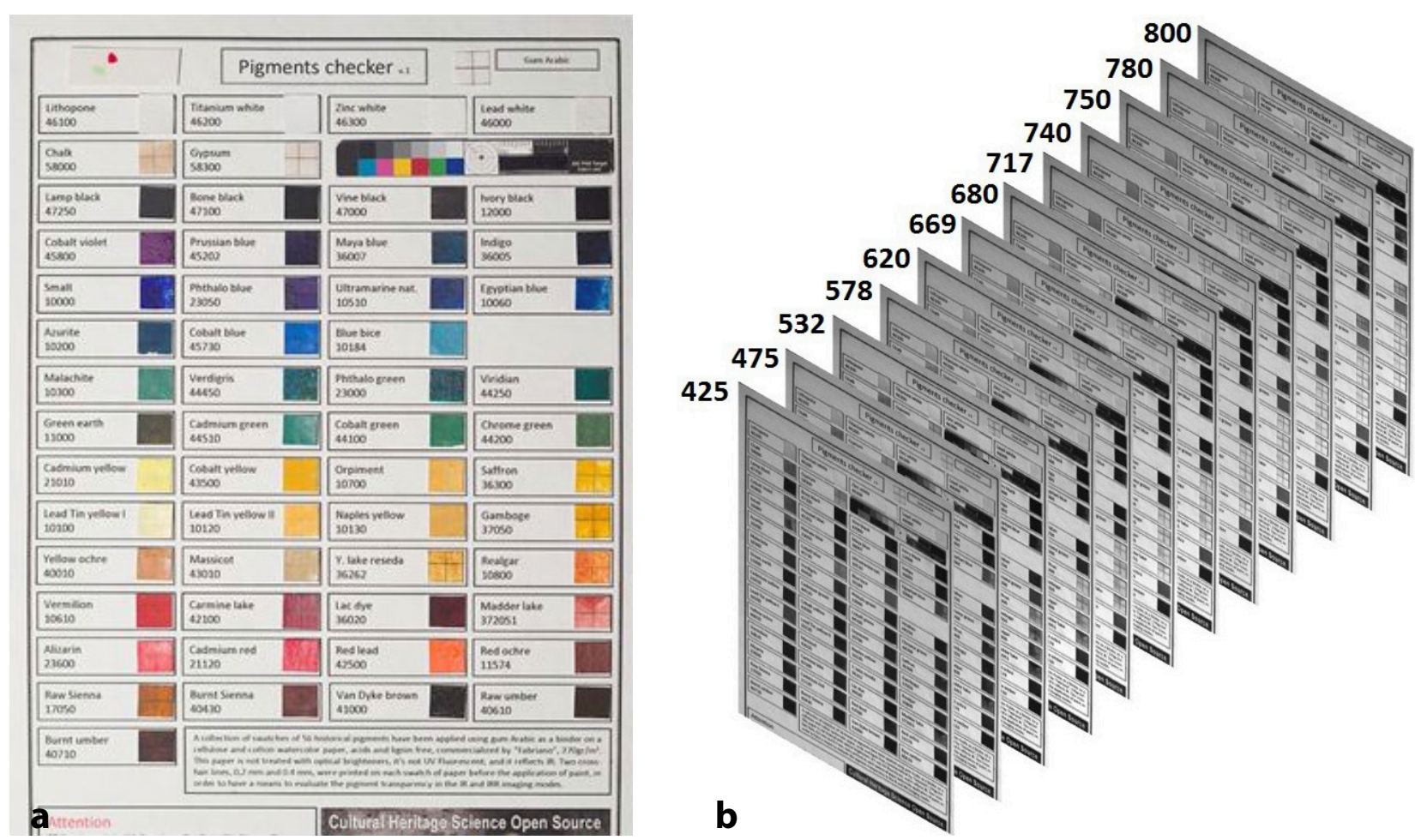

Figure 1. a) Photo of the pigments checker; $b$ ) MSI-12 images of the pigments checker (gum arabic).

resolution (bandwidth $10 \mathrm{~nm}$ ). The chosen 12 filters are (Figure 1b) (centre wavelength/bandwidth $\mathrm{nm}$ ): 425/50, 475/50, 532/16, 578/10, 620/10, 669/10, 680/10, 717/10, $740 / 10,750 / 10,780 / 20,800 / 10$. Also, the total spectral range recorded was shortened from the 360-1000 $\mathrm{nm}$ range supported by the CCD camera to the $400-805 \mathrm{~nm}$ range actually covered by the 12 filters, since this range seemed the most representative of the spectral features of the pigments, as will be discussed in this section. The UV region has been discarded and no filters have been chosen for this range. Indeed, a UV source would be needed in addition to the halogen lamps to record images in the UV, and this conflicts with the overall goal to keep the equipment as simple as possible. Discarding the UV region implies that it is not possible to register the UV absorption band that characterizes titanium white and zinc white. On the other hand, these two pigments, along with viridian, are the only ones that show features in the UV region and consequently the exclusion of this band was considered acceptable. Figure 2 shows the FORS and MSI-12 spectra of zinc white, titanium white, and lead white. The bars at the bottom of this and all the following graphs represent the central wavelength of each used filter and the corresponding bandwidth in $\mathrm{nm}$. Using this system, the MSI-12 spectra of the first two pigments do not capture the UV absorption band, and thus they do not appear to differ from lead white, which has a flat reflectance all over the UV-VIS-NIR range.

In the blue region, the characterizing spectral features are broad and vary slowly. Azurite and ultramarine are the most used historical blue pigments and they have reflectance maxima very close to each other, in the blue region at about $460 \mathrm{~nm}$ [29]. These maxima are adequately reconstructed in the corresponding MSI-12 spectra by 2 broad (bandwidth $50 \mathrm{~nm}$ ) filters in the blue region, centred at $425 \mathrm{~nm}$ and $475 \mathrm{~nm}$, and one green filter at $532 \mathrm{~nm}$ (bandwidth $16 \mathrm{~nm}$ ) (Figure 3). On the other hand, the two pigments can also be distinguished thanks to ultramarine's higher reflectance in the infrared. Similar arguments may be stated for the other pigments having maxima in the blue region and thus it was considered sufficient to cover this area with the 3 filters mentioned.

In the green region, the narrow $(16 \mathrm{~nm})$ filter at 532 $\mathrm{nm}$ is useful to reconstruct the reflectance maxima of some widely used green pigments. Indeed, this filter is centred at the reflectance maxima of malachite [30] and chrome green. Verdigris is another important copperbased pigment, with a reflectance maximum closer to the blue, at about $500 \mathrm{~nm}$. Figure 4 shows that the five filters at 425, 475, 532, 578 and $620 \mathrm{~nm}$ can reconstruct the maxima in all of these three pigments, and produce different spectra for each of them. In particular, the filters succeed in reconstructing both the narrow shape of the maxima of chrome green and verdigris, as well as the broad one of malachite.

The region between the far red and the near infrared requires higher resolution and it has been covered with two third of the 12 filters: 7 filters $(669,680,717,740$, $750,800 \mathrm{~nm}$ ) with bandwidth $10 \mathrm{~nm}$ and one filter centred at $780 \mathrm{~nm}$ with bandwidth $20 \mathrm{~nm}$. The combination of these filters is able to indicate the absorption bands in lithopone, a mixture of barium sulphate, a good flat 


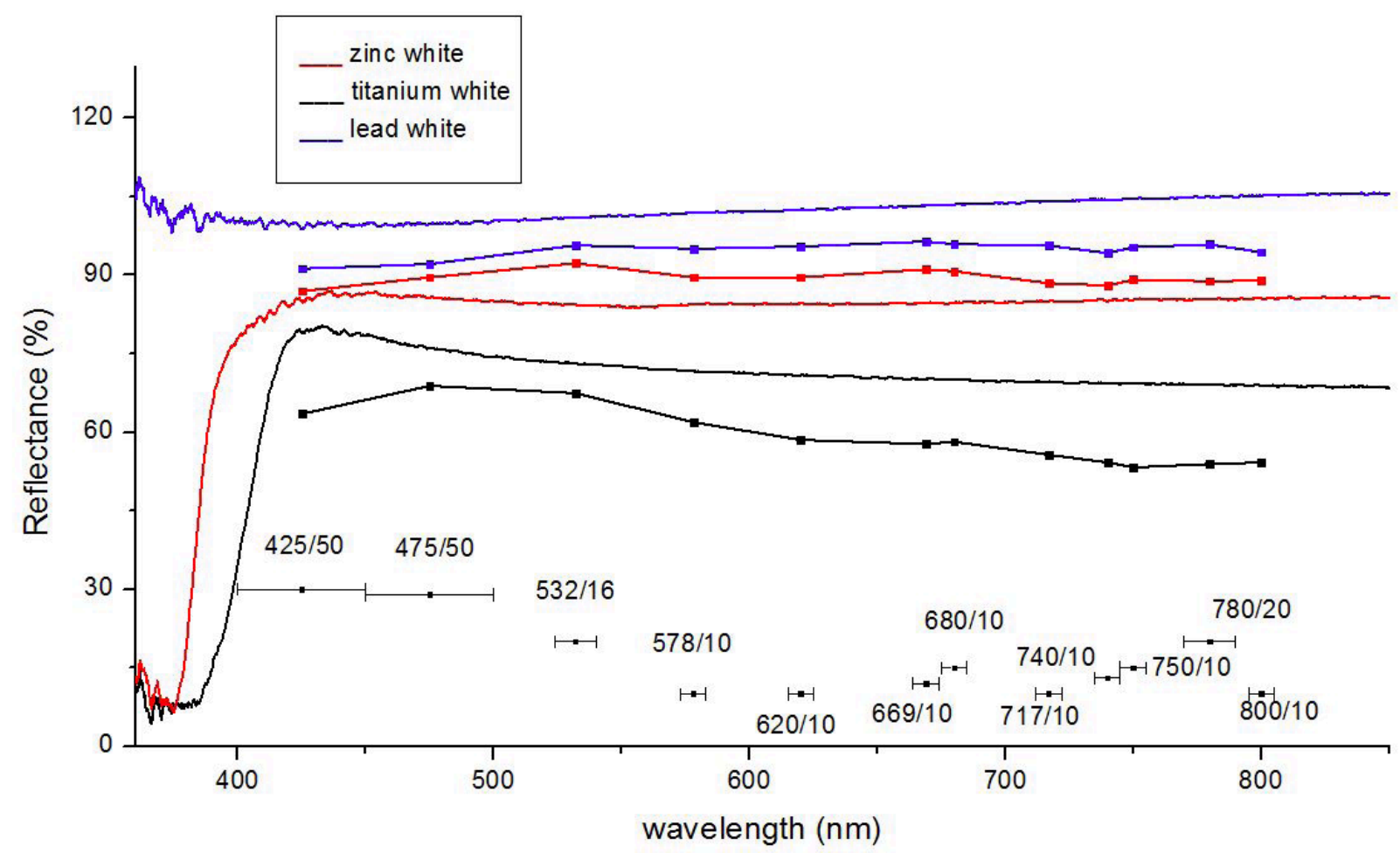

Figure 2. FORS (solid line) and MSI-12 (dotted line) spectra of zinc white, titanium white and lead white swatches.



Figure 3. FORS (solid line) and MSI-12 (dotted line) spectra of ultramarine and azurite swatches.

reflector [31], and zinc sulphide, which is responsible for absorption bands in the 650-800 $\mathrm{nm}$ region [32] (Figure 5). In the farthest part of the infrared region recorded both the absorption band of cobalt violet, and indigo's sharp increase in reflectance [33] are indicated (Figure 5). Other examples of characterizing spectral features in the infrared are given by realgar, which has an inflection point at 740 nm [31], and Egyptian blue, which has two absorption bands near $630 \mathrm{~nm}$ and $800 \mathrm{~nm}$ (Figure 6). The most challenging task for these 12 filters was to reconstruct the 


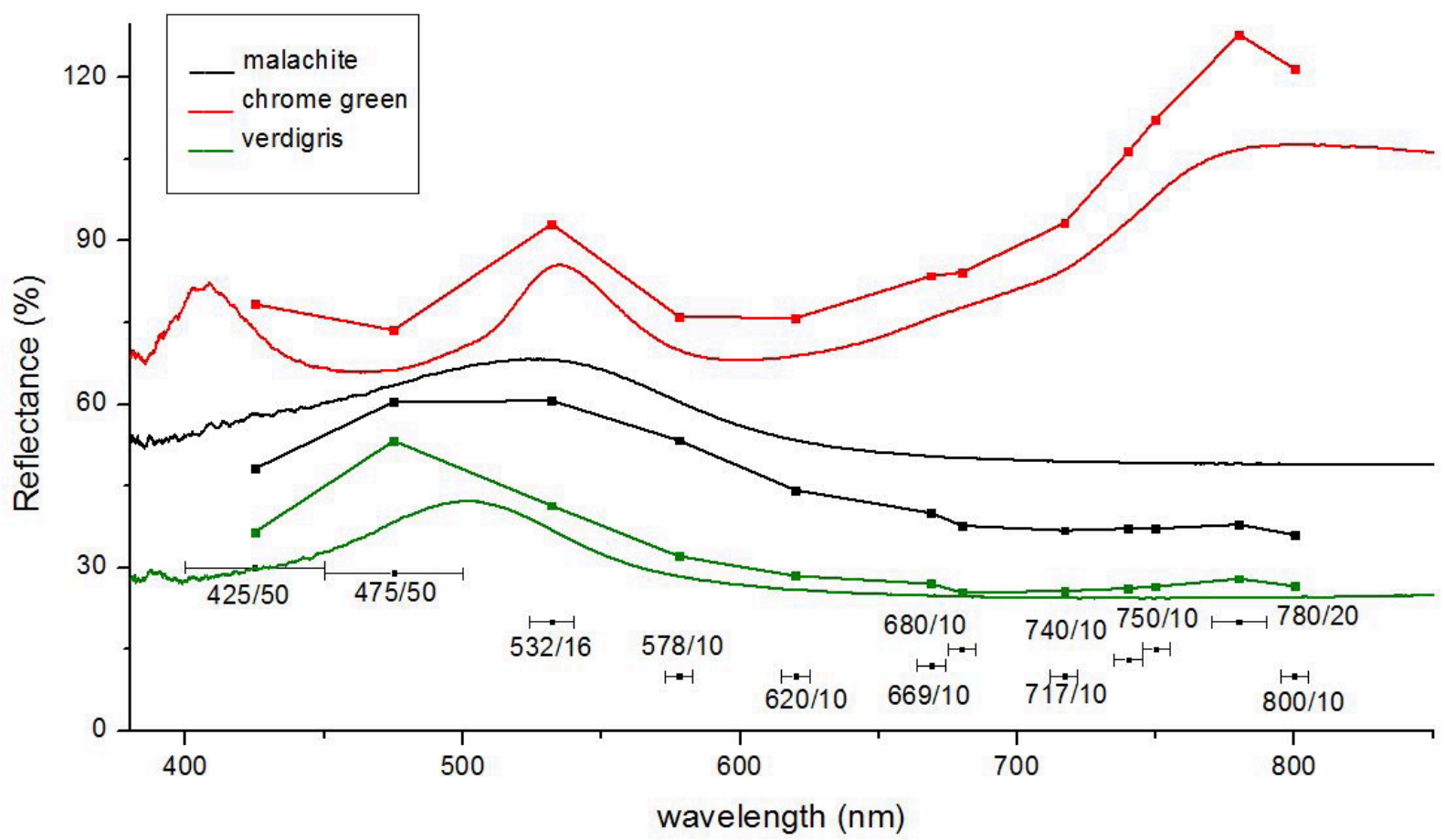

Figure 4. FORS (solid line) and MSI-12 (dotted line) spectra of malachite, chrome green and verdigris swatches.

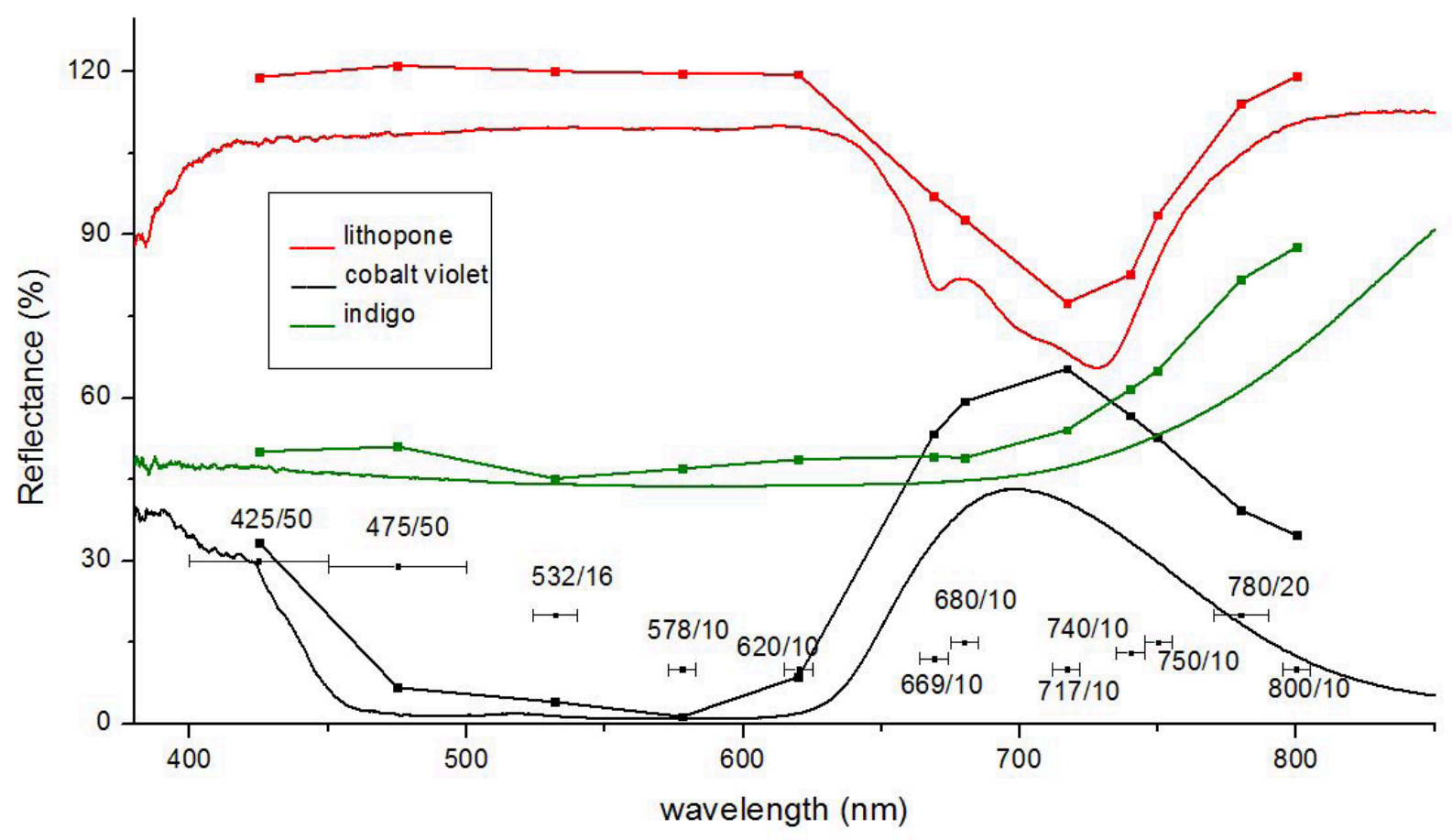

Figure 5. FORS (solid line) and MSI-12 (dotted line) spectra of lithopone, cobalt violet and indigo swatches.

S-shaped curves of yellow and red ochre, which span all the way from the green region to the infrared (Figure 7).

The identification of pigments becomes more effective by observing the features of the MSI-12 spectra across the entire VIS-NIR spectrum rather than focusing on specific regions, as has been discussed so far. For example, smalt is characterized by an absorbance band that is divided in three sub-bands with minima at $540 \mathrm{~nm}, 590 \mathrm{~nm}$ and 640 $\mathrm{nm}$ [34]. While these sub-bands can be observed in the FORS spectrum, they are lost in the MSI-12 spectrum. 


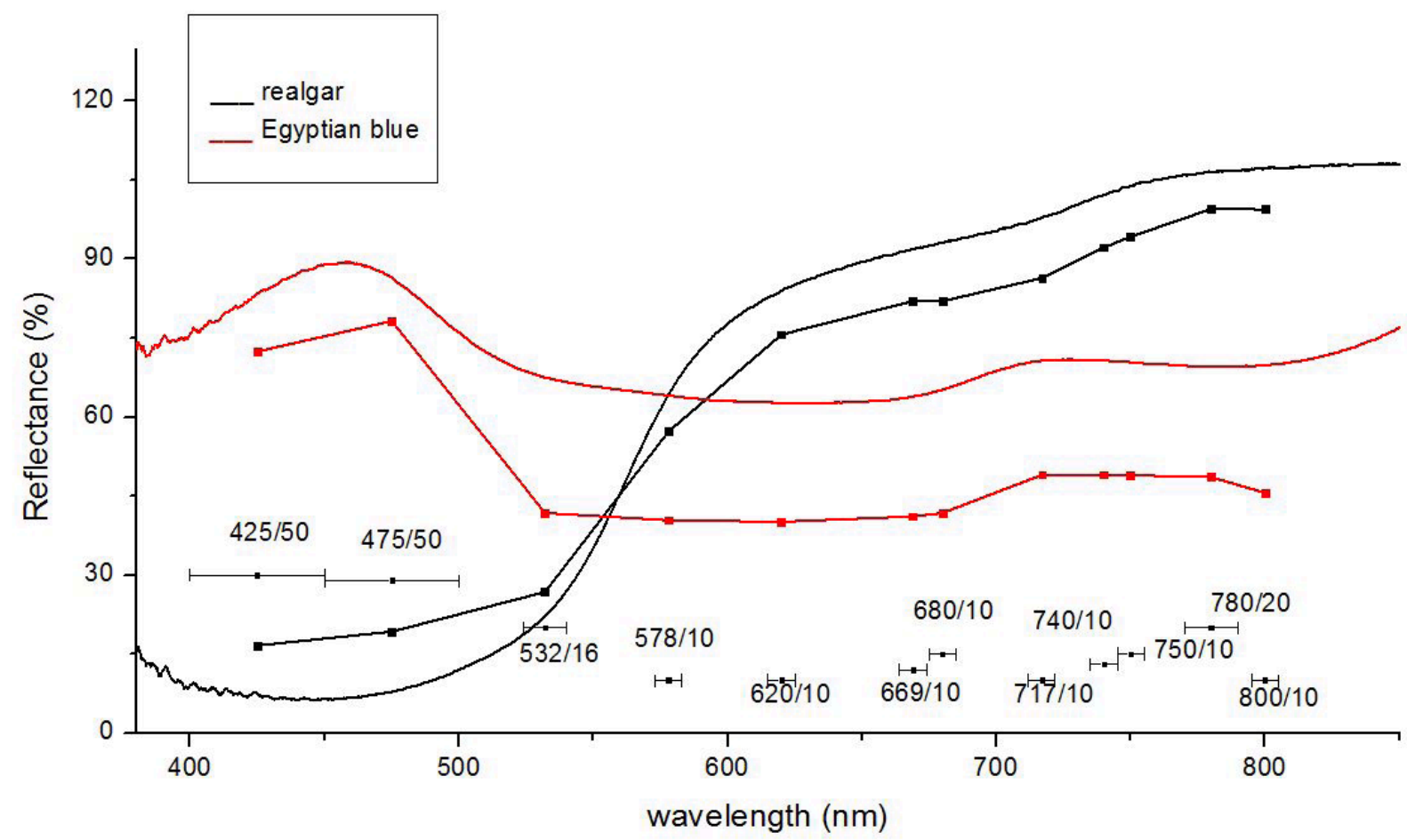

Figure 6. FORS (solid line) and MSI-12 (dotted line) spectra of realgar and Egyptian blue swatches.

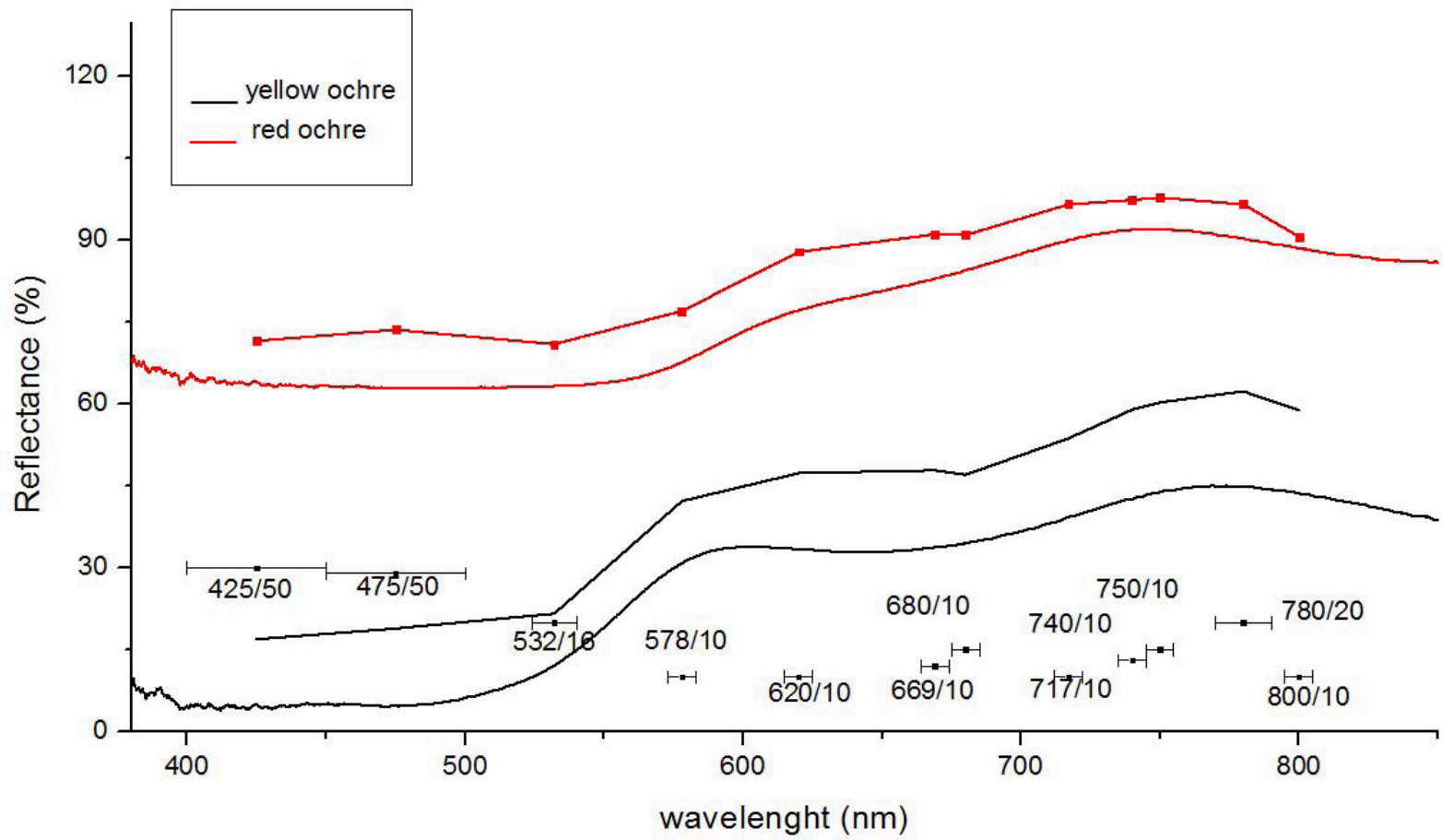

Figure 7. FORS (solid line) and MSI-12 (dotted line) spectra of yellow and red ochre swatches.

Nevertheless, smalt is also characterized by its large absorption band between the blue and the infrared region and by its high reflectance in the infrared. These features, as well as the reflectance maximum in the blue region (at about $415 \mathrm{~nm}$ ), are indicated in the MSI-12 spectra and are useful to distinguish smalt from other blue pigments that also reflect in the infrared, such as ultramarine (Figure 8).

Cadmium yellow and cobalt blue are two additional examples that show that it is important to examine the spectrum as a whole. The first 


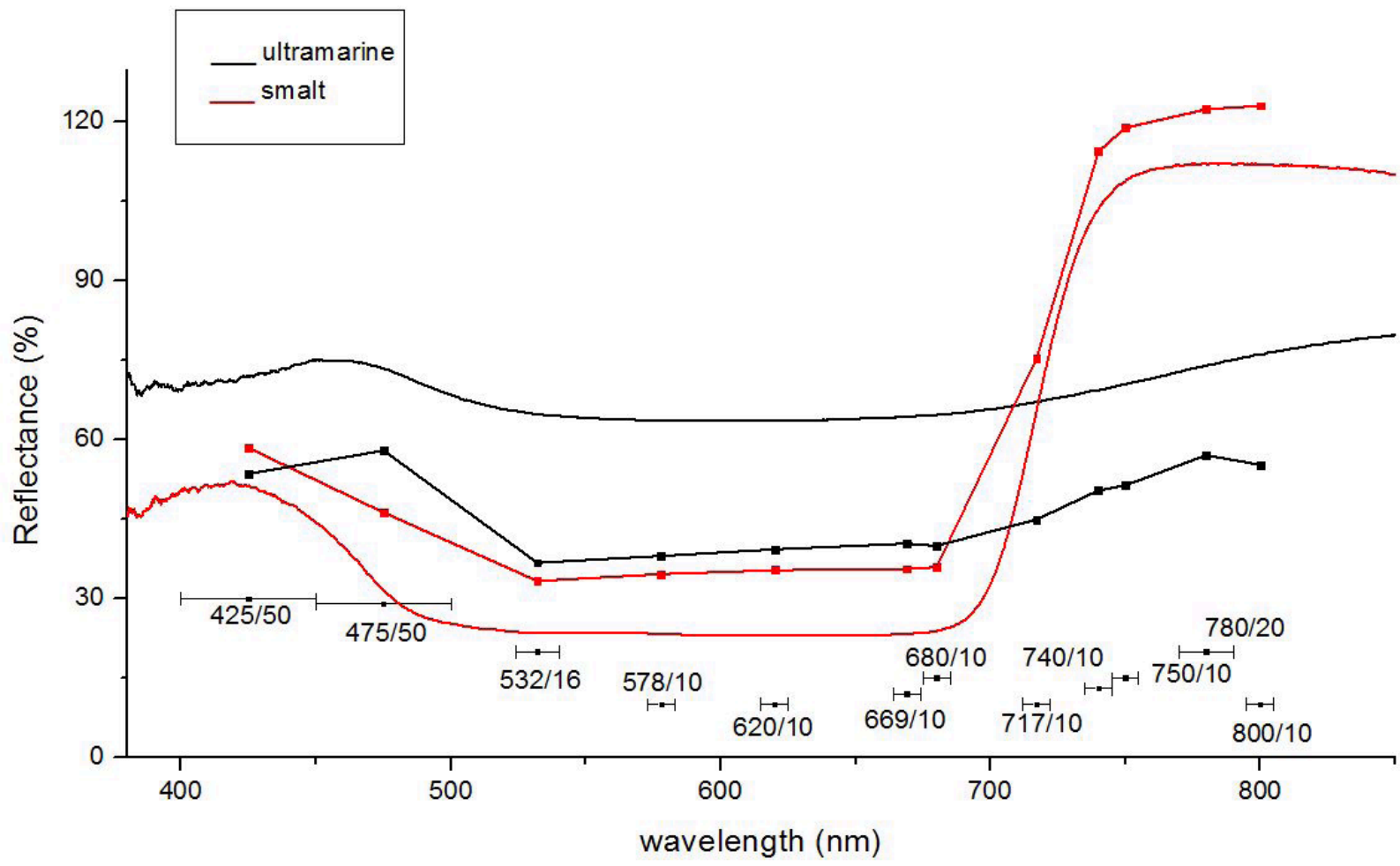

Figure 8. FORS (solid line) and MSI-12 (dotted line) spectra of smalt and ultramarine swatches.

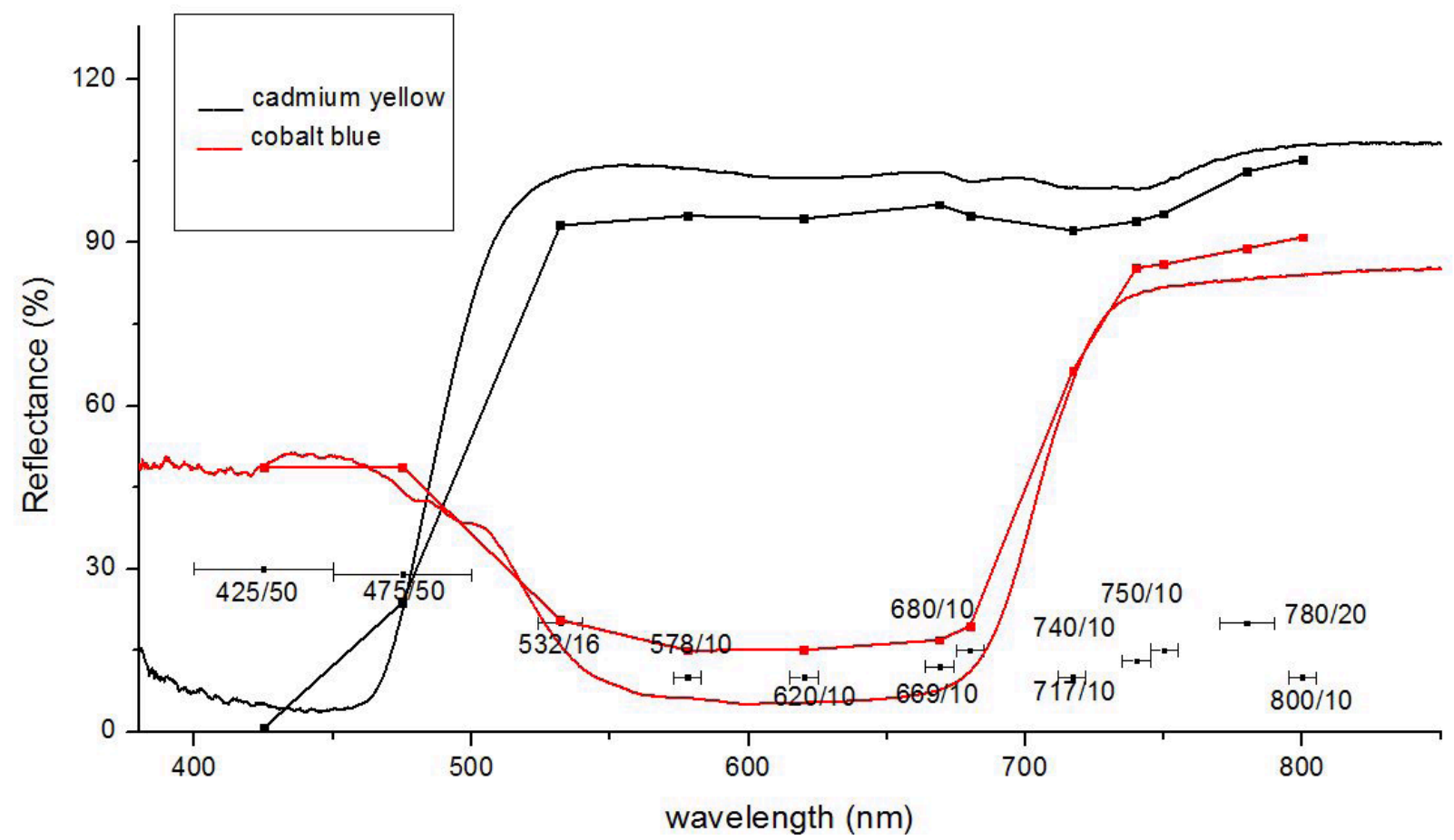

Figure 9. FORS (solid line) and MSI-12 (dotted line) spectra of cadmium yellow and cobalt blue swatches.

is identified thanks to the absorption bands of zinc sulphide in the infrared region and the sharp inflection point at about $490 \mathrm{~nm}$. The MSI-12 spectrum of cobalt blue is characterized by the absorption band in the $500-700 \mathrm{~nm}$ region and the flat reflectance from the blue region toward the UV (Figure 9).

The 12 filters give indications also on the sharp inflection points. In addition to the cadmium yellow previously described, Figure 10 shows pigments with 




Figure 10. FORS (solid line) and MSI-12 (dotted line) spectra of lead tin yellow I, cobalt yellow and vermilion swatches.



Figure 11. MSI-12 spectra of madder lake painted over vermilion and on cardboard, and vermilion painted on cardboard.

sharp inflection points in the blue (lead tin yellow I at 465 $\mathrm{nm}$ ), in the green (cobalt yellow at $525 \mathrm{~nm}$ ) and in the red region (vermilion at $600 \mathrm{~nm}$ ).
Reflectance spectroscopy is very sensitive to the presence of lakes and dyes, and it is very useful for the identification of glazes whose spectra are not modified 


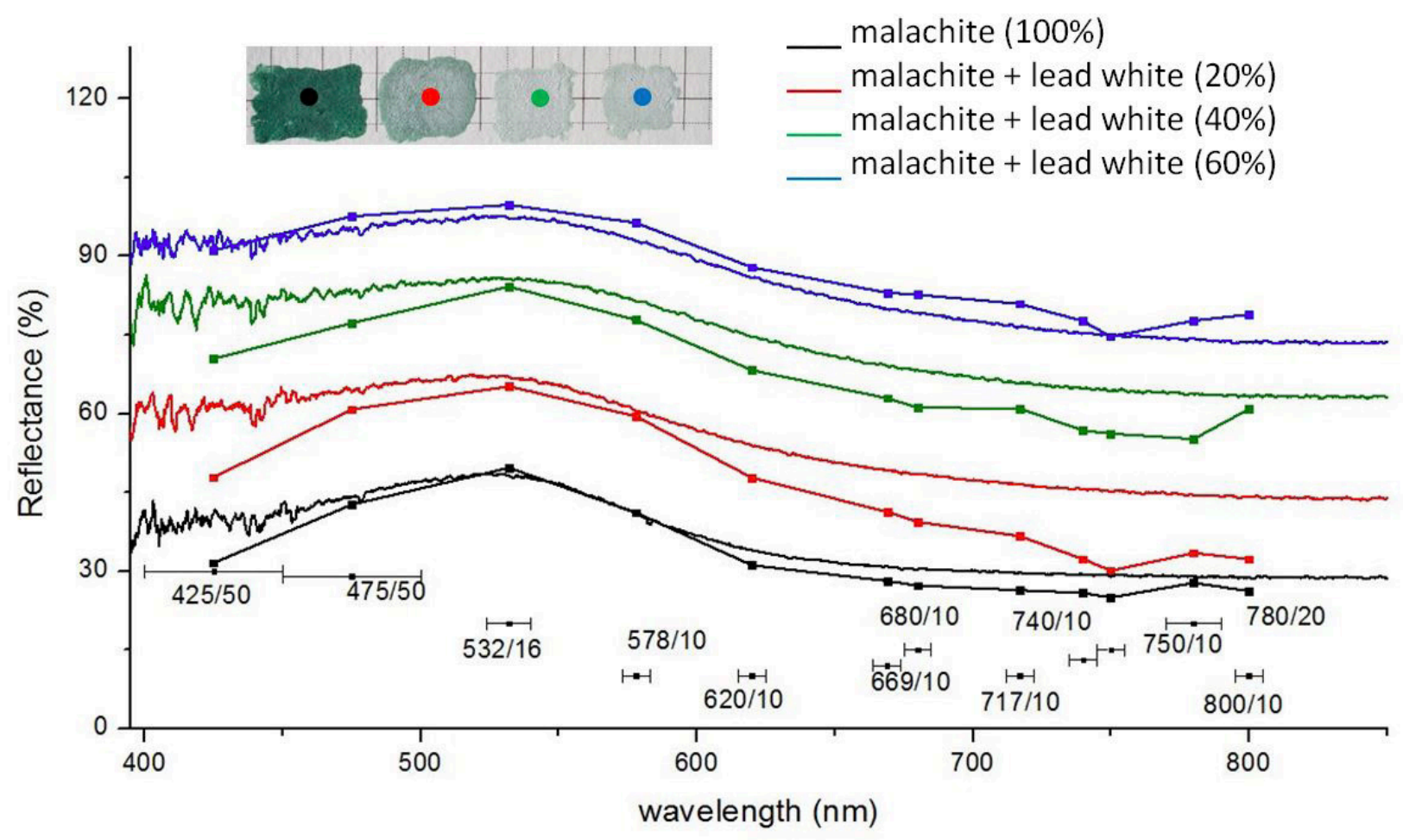

Figure 12. FORS (solid line) and MSI-12 (dotted line) spectra of malachite mixed with lead white.


Figure 13. Crucifix chapel, Flagellation scene. FORS (solid line) and MSI-12 (dotted line) spectra of points 16 and MSI-12 spectra of chrome green and green earth reference swatches.

by the under paint [35]. The same can be observed in the MSI-12 spectra. Figure 11 shows that the MSI-12 spectrum of madder lake glazed over vermilion is not affected by the under layer, and overlaps with that of madder lake painted over a white cardboard.

Regarding mixtures, the performance of the system is not comparable with that of a FORS system or a hyperspectral imager, but in simple mixtures the system can still be useful. Figure 12 shows the FORS and MSI12 spectra of malachite mixed with an increasing amount (by weight) of lead white $(0 \%, 20 \%, 40 \%, 60 \%)$. All of the MSI-12 spectra show the reflectance maximum of malachite, same as with the FORS spectra. This information is significant even if no assumption can 
be made on the proportion of the two pigments in the mixture.

The multispectral system was also tested on a series of frescoes revealed in 2012 during a restoration carried out in the Crucifix chapel of the Mother Church in the town of Aci Sant'Antonio, Sicily. The murals were preserved in each of the corners of the square chapel behind an early 20 th century counter wall. They have been the subject of a study [36, 37] using infrared and ultraviolet photography, portable XRF spectroscopy (pXRF), and FORS. Two scenes of the frescoes were analysed with this system: the Kiss of Judas and the Flagellation.

In the Flagellation scene, the XRF analysis of the green pigment in point 16 indicated iron and chrome as the main elements, suggesting a layer of green earth more recently retouched with a chrome based green pigment (viridian or the most commonly used chrome green). The MSI-12 spectrum matches the FORS one and both provide a reflectance maximum compatible with chrome green, while the lower reflectance in the infrared region can be attributed to the original green earth that absorbs the infrared (Figure 13).

Figure 14 shows the FORS and MSI-12 spectra of points 2, 3 and 4 on the bottom border of the Kiss of Judas scene. Point 2 was assigned to emerald green because of its copper and arsenic content indicated by the XRF analysis. The FORS and MSI-12 spectra are comparable and show a strong reflectance maximum at about $520 \mathrm{~nm}$. Unfortunately, a FORS reference spectrum for emerald green was not available to provide a direct comparison on the graph, however, the FORS spectrum from point 2 is compatible with the one reported in literature [38]. Point 3 is a bright yellow on the bottom border of the scene. XRF analysis identified it as chrome yellow and its FORS spectrum shows the pigment's sharp inflection point at $520 \mathrm{~nm}$ [39]. In this case, the MSI-12 spectrum failed to reconstruct this inflection point, which among the historical pigments, is the closest to the blue region and is located in the range covered at lower resolution. The under layer of paint on the bottom frame, point 4, is original and the XRF analysis confirmed a more usual yellow earth. This attribution is supported by FORS and MSI-12 spectra showing the characteristic S-shape of ochre.

Figure 15 illustrates the FORS and MSI-12 spectra of points 9, 11 and 12 on the Kiss of Judas scene. The XRF spectrum of point 9 showed only iron content, and pointed to a green earth as suggested by the FORS and MSI-12 spectra, where the resulting spectrum was flat, due to the fact that green earth has very weak absorption bands. The XRF spectrum of point 11 is rich in mercury, and both FORS and MSI-12 spectra confirmed the use of vermilion. Point 12, on the blue mantle of Jesus, showed only abundant lead content and some iron, in quantities comparable with that of the ground layer, thus no elements relating specifically to a blue colourant were found. Therefore, blue pigments based on metal elements: azurite $(\mathrm{Cu})$, cobalt blue and smalt $(\mathrm{Co})$, can be ruled out. On the other hand, FORS and MSI-12 spectra are consistent and also rule out indigo, pointing to Prussian blue mixed with lead white as the more likely attribution.

\section{Conclusions}

This paper introduced a set of 12 interference filters which combined with a CCD camera constitute an affordable multispectral imaging system for the mapping


Figure 14. Crucifix chapel, Kiss of Judas. FORS (solid line) and MSI-12 (dotted line) spectra of points 2, 3 and 4 and FORS of yellow ochre reference swatch. 

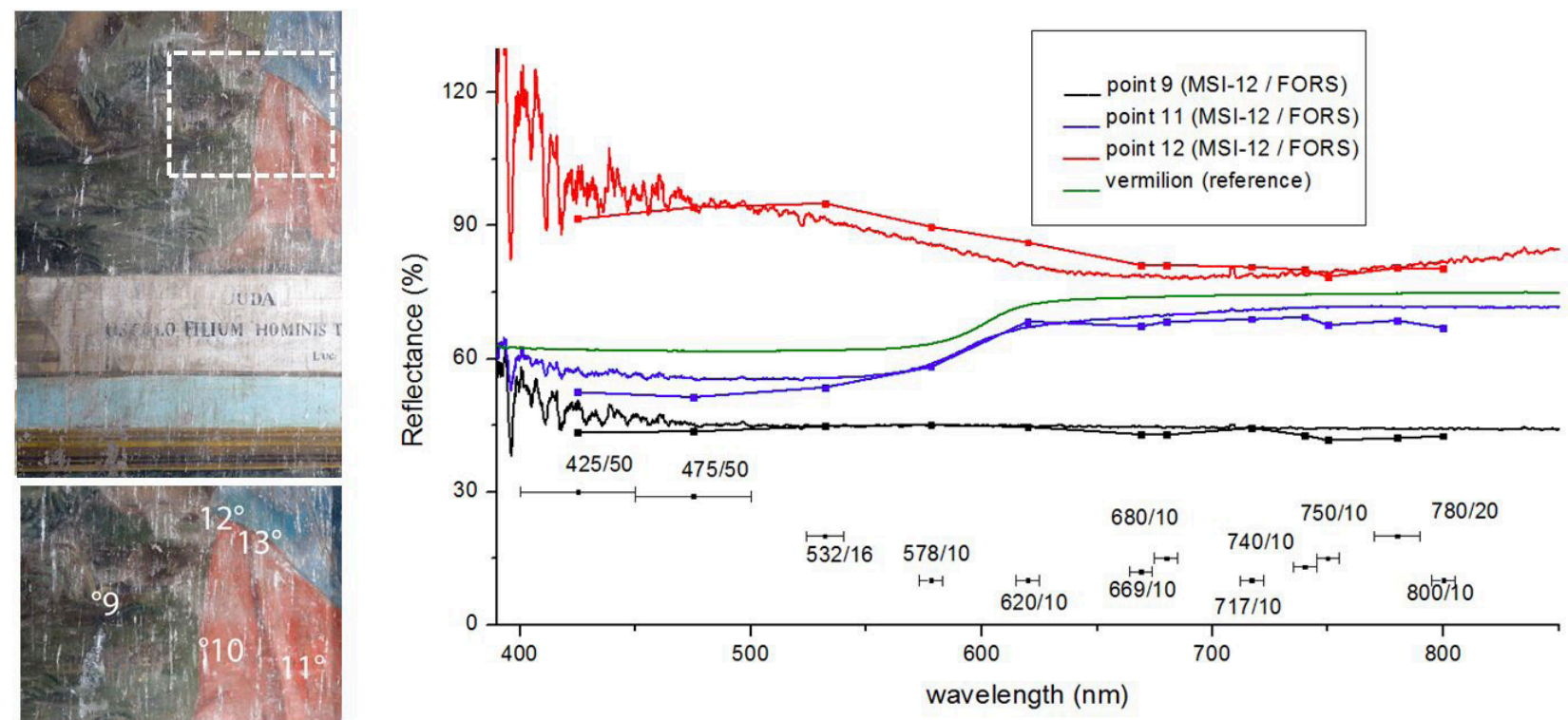

Figure 15. Crucifix chapel, Kiss of Judas. FORS (solid line) and MSI-12 (dotted line) spectra of points 9, 11 and 12 and FORS of vermilion reference swatch.

of historical pigments and their tentative identification. This system does claim only to provide a qualitative reconstruction of the reflectance spectra of the pigments for the sole scope of segmenting the images of polychrome art works. This system is indicated for the conservators which want to identify areas of interest for further analytical examination to achieve conclusive results.

The reasoning that led to the specific choice (center wavelength and bandwidth) of these filters set was discussed, with examples taken from the reconstructed reflectance spectra of a collection of 54 historical pigments. It was chosen to discard the UV region of the spectrum, since otherwise a strong UV lamp would need to be used together with the halogen ones or other continuous VIS-NIR sources. Consequently, this system cannot distinguish zinc white and titanium white, and cannot detect the reflectance maximum of viridian in the UV region.

On the other hand, the maxima of blue pigments and of some widely used green pigments such as malachite and chrome green were detected with the two broad $(50 \mathrm{~nm})$ filters in the blue region $(425,475 \mathrm{~nm})$ and the narrow $(16 \mathrm{~nm})$ green filter $(532 \mathrm{~nm})$. The reconstruction of the position and shape of these maxima aims only to be qualitative since the few number of filters does not allow for more accurate measurements.

The region between the red and the near infrared requires higher resolution, and it was covered with 8 narrow filters $(620,669,680,717,740,750,780,800$ $\mathrm{nm}$ ), which allowed the reconstruction of several complex absorption bands, such as that of lithopone in the 650-800 $\mathrm{nm}$ range, and the $\mathrm{S}$-shaped curves of yellow and red ocher. The 12 filters are able to indicate also the inflection points between the green and blue region, such as in the spectra of cadmium yellow, lead tin yellow I, cobalt yellow and vermilion.

The examination of the newly discovered $18^{\text {th }}$ century frescoes in the Mother Church of Aci Sant'Antonio (Sicily) provided the opportunity to test the system on real artworks, and to acquire the reflectance spectra of two pigments absent in the reference database of FORS spectra, emerald green and chrome yellow.

This system, composed of the most economic components, a CCD camera and a small set of interference filters, is of interest for the cultural heritage sector because of its hardware simplicity, ease of use, and acquisition speed, as well as the fact that its light weight and small dimensions make it easily portable. This must be considered as a preliminary study toward the definition of a best minimum set of filters. These filters are commercially available and have been chosen based on qualitative observations of the spectral features of historical pigments.

\section{Acknowledgments}

This work has been possible thanks to PixelTeq and Ocean Optics which kindly provided the SpectroCam VIS and the filters set presented in the paper.

\section{References}

1 Delaney, J. K.; Ricciardi, P.; Glinsman, L. D.; Facini, M.; Thoury, M.; Palmer, M.; de la Rie, E. R., 'Use of imaging spectroscopy, fiber optic reflectance spectroscopy, and X-ray fluorescence to map and identify pigments in illuminated manuscripts', Studies in Conservation, 59(2) (2014) 91-101, doi:10.1179/2047058412Y.0000000078. 
2 Toque, J. A.; Sakatoku, Y.; Ide-Ektessabi, A., 'Pigment identification by analytical imaging using multispectral imaging', in 16th IEEE International Conference on Image Processing, Cairo (2009) 2861-2864, doi:10.1109/ ICIP.2009.5414508.

3 Fischer, C., Kakoulli, L.; 'Multispectral and hyperspectral imaging technologies in conservation: current research and potential applications', Reviews in Conservation, 7 (2006) 3-16, doi:10.1179/sic.2006.51.Supplement-1.3.

4 Pelagotti, A.; Del Mastio, A.; Cappellini, V., 'Multispectral and multi-modal imaging data processing for the identification of painting materials', in Lasers in the Conservation of Artworks, ed. M. Castillejo, P. Moreno, M. Oujja, R. Radvan and J. Ruiz, Taylor \& Francis Group, London (2008) 454-458.

5 Liang, H., 'Advances in multispectral and hyperspectral imaging for archaeology and art conservation', Applied Physics A, 106(2) (2012), 309-323, doi:10.1007/s00339011-6689-1.

6 Attas, M.; Cloutis, E.; Collins, C.; Goltz, D.; Majzels, C.; Mansfield, J. R.; Mantsch, H. H., 'Near-infrared spectroscopic imaging in art conservation: investigation of drawing constituents', Journal of Cultural Heritage, 4(2) (2003) 127-136, doi:10.1016/S1296-2074(03)00024-4.

7 Liang, H.; Keita, K.; Pannell, C.; Ward, J., 'A SWIR Hyperspectral imaging system for art history and art conservation', in IX Congreso Nacional del Color, Publicaciones de la Universidad de Alicante, Alicante (2010) 189-192.

8 Delaney, J. K.; Zeibel, J. G.; Thoury, M.; Littleton, R.; Palmer, M.; Morales, K. M.; René de la Rie, E.; Hoenigswald A., 'Visible and infrared imaging spectroscopy of Picasso's, Harlequin Musician: mapping and identification of artist materials in situ', Applied Spectroscopy, 64(6) (2010) 584594, doi:10.1366/000370210791414443.

9 Zhao, Y.; Berns, R. S.; Taplin, L. A.; Coddington, J., 'An investigation of multispectral imaging for the mapping of pigments in paintings', in Computer Image Analysis in the Study of Art, ed. D. G. Stork and J. Coddington, SPIE, San Jose, CA (2008) 681007, doi:10.1117/12.765711.

10 Blazek, J.; Soukup, J.; Zitova, B.; Flusser, J.; Tichy, T.; Hradilova, J., 'Low-cost mobile system for multispectral cultural heritage data acquisition', in Digital Heritage International Congress IEEE, IEEE, Marseille (2013) 7379, doi:10.1109/DigitalHeritage.2013.6743715.

11 Cosentino, A., 'A practical guide to panoramic multispectral imaging', e-conservation Magazine 25 (2013) 64-73, $\mathrm{http} / / / \mathrm{ww} w . e-c o n s e r v a t i o n l i n e . c o m / c o n t e n t / v i e w / 1100$.

12 Melessanaki, K.; Papadakis, V.; Balas, C.; Anglos, D., 'Laser induced breakdown spectroscopy and hyper-spectral imaging analysis of pigments on an illuminated manuscript', Spectrochimica Acta Part B 56(12) (2001) 2337-2346, doi:10.1016/S0584-8547(01)00302-0.

13 Dooley, K. A.; Lomax, S.; Zeibel, J. G.; Miliani, C.; Ricciardi, P.; Hoenigswald, A.; Loew, M.; Delaney, J. K., 'Mapping of egg yolk and animal skin glue paint binders in Early Renaissance paintings using near infrared reflectance imaging spectroscopy', Analyst, 138(17) (2013) 4838-4848, doi:10.1039/C3AN00926B.

14 Kim, S. J.; Deng, F.; Brown, M. S., 'Visual enhancement of old documents with hyperspectral imaging', Pattern Recognition, 44(7) (2011) 1461-1469, doi:10.1016/j. patcog.2010.12.019.

15 Padoan, R.; Steemers, T.; Klein, M.; Aalderink, B.; De Bruin, G., 'Quantitative hyperspectral imaging of historic documents', in Proceedings of the 9th International Conference on NDT of Art, Jerusalem (2008), http://www. ndt.net/article/art2008/papers/097Padoan.pdf.

16 Lettner, M.; Diem, M.; Sablatnig, R.; Miklas, H., 'Registration and enhancing of multispectral manuscript images', in 16th European Signal Processing Conference (EUSIPCO 2008), EURASIP, Lausanne (2008), http:// www.eurasip.org/Proceedings/Eusipco/Eusipco2008/ papers/1569104892.pdf.

17 Art Innovation, http://art-innovation.nl (accessed 8-4-2015).

18 DySIS Medical, http://www.forth-photonics.com (accessed 8-4-2015).

19 Carcagni, P.; Della Patria, A.; Fontana, R.; Greco, M.; Mastroianni, M.; Materazzi, M.; Pampaloni, E.; Pezzati, L., 'Multispectral imaging of paintings by optical scanning', Optics and Lasers in Engineering 45(3) (2006) 360-367, doi:10.1016/j.optlaseng.2005.02.010.

20 Ribés, A.; Schmitt, F.; Pillay, R.; Lahanier, C., 'Calibration and spectral reconstruction for Crisatel: an art painting multispectral acquisition system', Journal of Imaging Science and Technology 49(6) (2005) 563-573.

21 Kubik, M., 'Hyperspectral imaging: a new technique for the non-invasive study of artworks', in Physical Techniques in the Study of Art, Archaeology and Cultural Heritage, vol 2, ed. D. C. Creagh and D. Bradley, Elsevier (2007) 199-259, doi:10.1016/S1871-1731(07)80007-8.

22 Ware, G. A.; Chabries, D. M.; Christiansen, R. W.; Brady, J. E.; Martin, C. E., 'Multispectral analysis of ancient Maya pigments: implications for the Naj Tunich corpus', IEEE Transactions 6 (2000) 2489-2491 doi:10.1109/ IGARSS.2000.859616.

23 Sakatoku, Y.; Toque, J. A.; Ide-Ektessabi, A., 'Reconstruction of hyperspectral image from multispectral image based on regression analysis: optimum regression model and channel selection', in Proceeding of the International Joint Conference on Computer Vision, Imaging and Computer Graphics Theory and Applications, Lisbon, Portugal (2009).

24 Ricciardi, P.; Delaney, J. K.; Glinsman, L. D.; Thoury, M.; Facini, M.; de la Rie, E. R., 'Use of visible and infrared reflectance and luminescence imaging spectroscopy to study illuminated manuscripts: pigment identification and visualization of underdrawings', in Proceedings of SPIE, O3A: Optics for Arts, Architecture, and Archaeology II. ed. L. Pezzati and R. Salimbeni, SPIE, Bellingham (2009) 739106-12, doi:10.1117/12.827415.

25 Liang, H.; Saunders, D.; Cupitt, J., 'A new multispectral imaging system for examining paintings', Journal of Imaging Science and Technology, 49(6) (2005) 551-562.

26 Rasband, W. S., ImageJ, U. S. National Institutes of Health, Bethesda, Maryland, http://imagej.nih.gov/ij/ (1997-2014).

27 Cosentino, A., 'Identification of pigments by multispectral imaging a flowchart method', Heritage Science 2 (2014) 8, doi:10.1186/2050-7445-2-8.

28 Cosentino, A., 'FORS spectral database of historical pigments in different binders', e-conservation Journal 2 (2014) 57-68, http://e-conservation.org/issue-2/36-FORS-spectraldatabase.

29 Bacci, M.; Baldini, F.; Carlà, R.; Linari, R., 'A color analysis of the Brancacci Chapel Frescoes', Applied Spectroscopy 45(1) (1991) 26-31, doi:10.1366/0003702914337713.

30 Picollo, M.; Bacci, M.; Casini, A.; Lotti, F.; Porcinai, S.; Radicati, B.; Stefani, L., 'Fiber optics reflectance spectroscopy: a non-destructive technique for the analysis of works of art', in Optical Sensors and Microsystems: New concepts, Materials, Technologies, ed. S. Martellucci, A. N. Chester and A. G. Mignani, Kluwer Academic - Plenum Publishers, New York (2000) 259-265, doi:10.1007/0-30647099-3_23.

31 Sanches, I. D.; Tuohy, M. P.; Hedley, M. J.; Bretherton, M. R., 'Large, durable and low-cost reflectance standard for field remote sensing applications', International Journal of Remote Sensing, 30(9) (2009) 2309-2319, doi:10.1080/01431160802549377. 
32 Boselli, L.; Ciattini, S.; Galeotti, M.; Lanfranchi, M. R.; Lofrumento, C.; Picollo, M.; Zoppi, A., 'An unusual white pigment in la Verna sanctuary frescoes: an analysis with micro-Raman, FTIR, XRD and UV-VIS-NIR FORS', E-Preservation Science 6 (2008) 38-42, http://www.moranartd.com/e-preservationscience/2009/Boselli-23-05-2008. pdf.

33 Leona, M.; Casadio, F.; Bacci, M.; Picollo, M, 'Identification of the pre-Columbian pigment maya blue on works of art by noninvasive UV-VIS and Raman spectroscopic techniques', Journal of the American Institute for Conservation 43(1) (2004) 39-54, doi:10.2307/3179850.

34 Depuis, G.; Elias, M.; Simonot, L., 'Pigment identification by fiber-optics diffuse reflectance spectroscopy', Applied Spectroscopy, 56(10) (2002) 1329-1336, doi:10.1366/00037 0202760354803 .

35 Bisulca C.; Picollo M.; Bacci M.; Kunzelman D., 'UV-VisNIR reflectance spectroscopy of red lakes in paintings', in Art2008: Proceedings of the 9th International Conference on Non-destructive Investigations and Microanalysis for the Diagnostics and Conservation of Cultural and Environmental Heritage, Jerusalem (2008), http://www.ndt. net/article/art2008/papers/199Bisulca.pdf.

36 Cosentino, A.; Stout, S.; Di Mauro, R.; Perondi, C., 'The Crucifix Chapel of Aci Sant'Antonio: newly discovered frescoes', Archeomatica 2 (2014) 36-42, http://issuu.com/geomedia/docs/archeomatica_2_2014?e=1225360/9272033.

37 Cosentino, A.; Gil, M.; Ribeiro, M.; Di Mauro, R., 'Technical photography for mural paintings: the newly discovered frescoes in Aci Sant'Antonio (Sicily, Italy)', Conservar Património 20 (2014), 23-33, doi:10.14568/ cp2015001.
38 Fiedler, I.; Bayard, M.. 'Emerald green and Scheele's green', in Artists' Pigments. A Handbook of Their History and Characteristics, ed. E. W. FitzHugh, vol. 3, National Gallery of Art, Washington (1997) 219-271.

39 Kühn, H.; Curran, M. 'Chrome yellow and other chromate pigments', in Artists' Pigments. A Handbook of Their History and Characteristics, ed. R. L. Feller, vol. 1, National Gallery of Art, Washington (1986) 187-217.

Received:: 17 April 2015

Revised: 16 May 2015

Accepted: 24 May 2015

Online: 10 June 2015

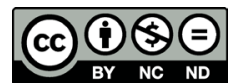

This work is licensed under the Creative Commons Attribution-NonCommercial-NoDerivs 3.0 Unported License.

To view a copy of this license, visit http://creativecommons.org/licenses/by-nc-nd/3.0/deed.pt. 